\title{
DETERMINATION OF SILVER NANOPARTICLES IN LIQUID ENVIRONMENTAL SAMPLES
}

\author{
GAJEC, M.* - KuKULSKA-ZAJĄC, E. - KRÓL, A. \\ Oil and Gas Institute - National Research Institute, 25A Lubicz Str., 31-503 Krakow, Poland \\ ${ }^{*}$ Corresponding author \\ e-mail: gajec@inig.pl
}

(Received 21 $1^{\text {st }}$ Feb 2020; accepted $2^{\text {nd }}$ Jul 2020)

\begin{abstract}
With the rapid increase of nanomaterial production and application, their incidental, accidental and intentional release into the environment is inevitable. Most nanoparticles (NPs) could be highly reactive, even those conventionally considered to be inert (e.g., $\mathrm{TiO}_{2}$ and $\mathrm{Au}$ ). Environmental transformation can remarkably alter the physicochemical properties of NPs, and consequently, their fate, transport and biological effects. Meanwhile, current facilities for wastewater treatment and waste management are not equipped to remove nanoparticles effectively and prevent their entry into the environment. The effluent from urban wastewater treatment plants (WWTPs) is considered a significant source of manufactured nanomaterial emissions into aquatic and terrestrial environments. Dissecting how the properties of nanoparticles may change once released into the environment is urgently needed to improve our understanding of their toxic effects in the environment. For this purpose, specialized methods are needed to recognize, separate and characterize nanoparticles in complex environmental media. The aim of the study was to determine silver nanoparticles in liquid environmental samples collected in Poland (surface water, treated sewage, tap water, water extraction of waste from the oil and gas mining industry) using single particle inductively coupled plasma mass spectrometry (sp ICP-MS).
\end{abstract}

Keywords: $N P s, A g N P s$, sp ICP-MS, surface water, inductively coupled plasma mass spectrometry

\section{Introduction}

Advances in nanotechnology are forecast to have a major impact on a broad range of industry sectors. The very large surface area of these nanomaterials may cause novel physical and chemical properties, such as increased catalytic activity, improved solubility or different optical behaviour. Nanotechnology offers many advantages. It allows for miniaturization, cost reduction, more sustainable use of resources among many others. Due to all its promises, nanotechnology has found an application across the fields of science and technology, ranging from scientific materials, electronics through energy, cosmetics, and agriculture to medicine, implants, and sensors. Metal nanoparticles are also widely used in the oil and gas industry sectors, e.g. during exploration, characterization of a field, drilling, cementing, production and stimulation, enhanced oil recovery (EOR), refining and processing (Krasodomski et al., 2013; Zima, 2017). The nanotechnology industry is rapidly generating new forms of waste streams because of the production and use of engineered nanomaterials (ENMs); however, only limited literature on the fate, behaviour and impacts of these waste streams on the environment and human health is available (Krasodomski et al., 2009; Aznar et al., 2013).

With the rapid increase of nanomaterials production and application, their incidental, accidental and intentional release into the environment is inevitable, and diverse types of engineered nanomaterials (ENMs), e.g., nano $\mathrm{Ag}$ and $\mathrm{TiO}_{2}$, have already been detected in various environmental media (Kim, 2010; Weinberg et al., 2011; Wagner et al., 2014). Increased production and widespread use of nanomaterials can lead to NPs 
migrating into the environment and interacting with organisms. Nanoparticles can be transported through air, water and soil and the process depends on their characteristics including size, charge, solubility, diffusion, deposition, bioavailability and biodegradability. Nanomaterials (NM) can be released into the environment in three ways: (1) during production, (2) during use, and (3) end-of-life release of products containing nanoparticles (from waste).

The release pattern and mass depend on the NP's type and its application. Metal containing nanoparticles are a significant class because their use in consumer and industrial applications makes them the fastest growing category of nanoparticles (Prasad et al., 2017). Particularly, silver nanoparticles (AgNPs) are used in many consumer products because of their proved antimicrobial properties attributable to the release of $\mathrm{Ag}^{+}$.

The environmental impact of silver nanoparticles (AgNPs) has become a topic of interest recently, this is due to the fact that AgNPs have been included in numerous consumer products including textiles, domestic appliances, food containers, cosmetics, paints and nano-functionalised plastics. Various applications have been found in the medical field for Ag NPs; for example, they can be used for biosensors, drug delivery systems, and medical devices (Bundschuh et al., 2018).

The production, use and disposal of these AgNP containing products are potential routes for environmental exposure. Therefore, in the near future, we can expect accumulation of NPs in the environment, which can have major implications for human health and environment. Although some information on NPs emission is available, it is of high importance to quantify their amounts and concentrations in the environment. Moreover, during deposition NPs can undergo physical, chemical and biological transformations (by redox reactions, dissolution, sorption of contaminant, or bioaccumulation) forming substances of different properties and toxicity than their native form. Therefore, both NPs forms, native and after conversion, should be monitored. As a result, there is a growing need for a rapid, accurate, sensitive technique for characterizing and quantifying NPs in a wide range of sample types. Specifically, techniques are needed to determine the size and concentration of NPs in complex matrices.

The basic parameter characterizing nanomaterials is the size of their particles and the distribution of this size. At present, there are several well-known methods for such a characterization (Laborda et al., 2016). Table 1 presents methods of nanoparticles separation from matrices of environmental samples as well as analytical techniques currently used in nanoparticles testing.

The process of nanoparticle determination consists of three basic stages: sampling and sample preparation, nanoparticle separation and identification. Sampling and preparation of the sample is a critical step in the process of nanoparticle determination as it may affect the state of dispersion. The stage of sample preparation depends to a large extent on the type of matrix being tested. Ideal sample preparation should be optimized by finding the right balance between reducing the matrix effects of the sample and maintaining its representativeness. The analysis of the data collected in Table 1 shows that nanoparticles are separated by centrifugation, ultrafiltration, cloud point extraction (CPE) and flow fractionation in an asymmetric flow field (AF4). Due to the complexity of environmental matrices, nanoparticle separation techniques should take into account, among others, the selectivity against NPs and the influence of interference from the matrix (Majedi et al., 2016). 
Table 1. List of methods of nanoparticle separation and techniques for their determination in various types of matrices (Laborda et al., 2016)

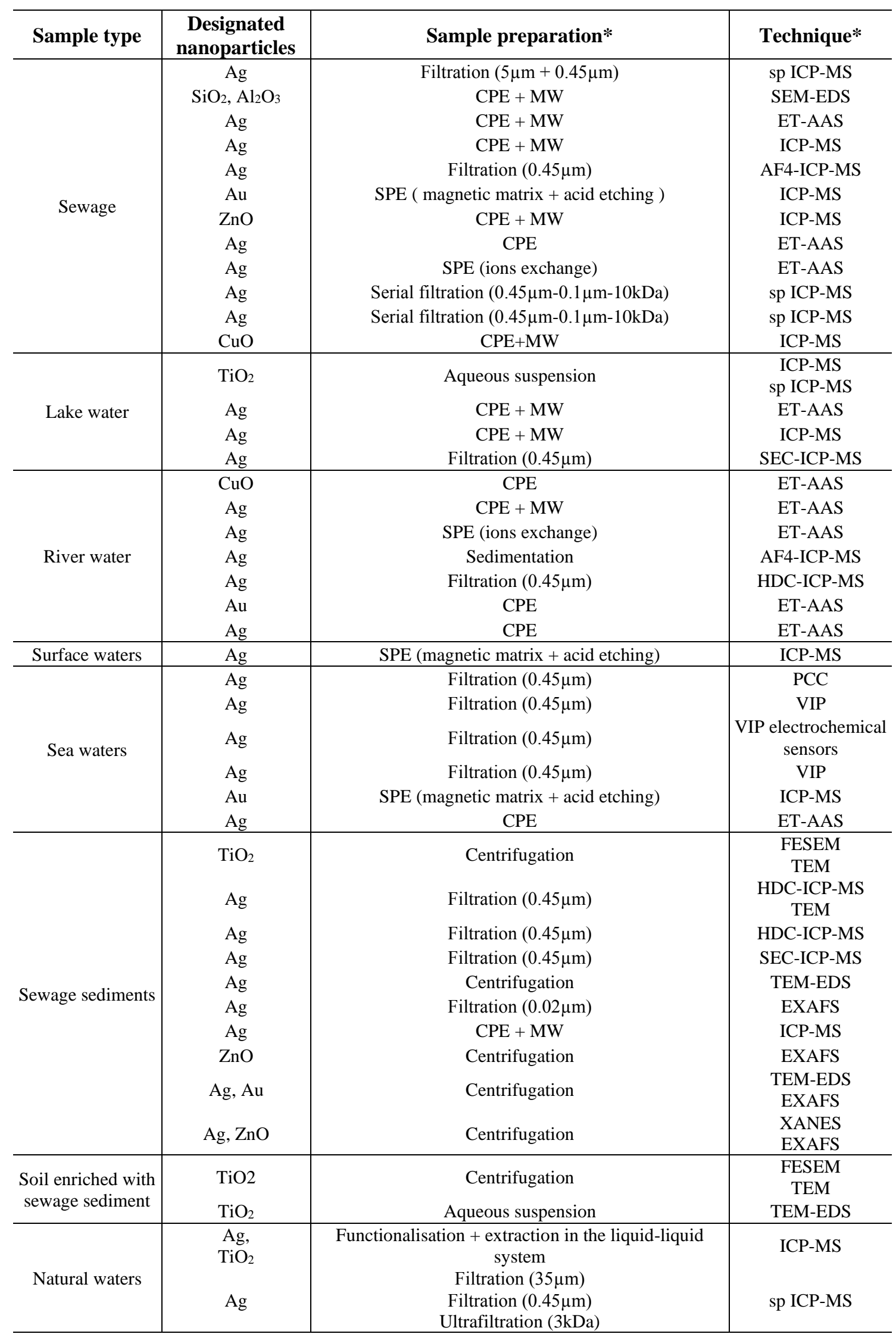




\begin{tabular}{|c|c|c|c|}
\hline Fresh waters & $\mathrm{Au}$ & $\begin{array}{c}\text { SPE (magnetic matrix }+ \text { acid etching) } \\
\text { Filtration }(35 \mu \mathrm{m}) \\
\text { Filtration }(0.45 \mu \mathrm{m}) \\
\text { Ultrafiltration }(3 \mathrm{kDa}) \\
\end{array}$ & $\begin{array}{l}\text { ICP-MS } \\
\text { NTA } \\
\text { DLS } \\
\text { UV-Vis }\end{array}$ \\
\hline Soil extract & $\mathrm{Ag}$ & Filtration $(0.45 \mu \mathrm{m})$ & AF4-ICP-MS \\
\hline Soil & $\begin{array}{l}\mathrm{Au} \\
\mathrm{Ag} \\
\mathrm{Ag}\end{array}$ & $\begin{array}{c}\text { Centrifugation } \\
\text { Ultrafiltration } \\
\text { Filtration }(0.02 \mu \mathrm{m}) \\
\end{array}$ & $\begin{array}{l}\text { ESEM } \\
\text { FESEM } \\
\text { ESEM } \\
\text { FESEM } \\
\text { EXAFS }\end{array}$ \\
\hline Artificial sea water & $\mathrm{Ag}$ & Filtration $(0.45 \mu \mathrm{m})$ & $\begin{array}{c}\text { AF4-ICP-MS } \\
\text { sp ICP-MS }\end{array}$ \\
\hline Sewage sediment & $\mathrm{Au}$ & Ultracentrifugation & $\begin{array}{l}\text { ESEM } \\
\text { FESEM } \\
\text { TEM } \\
\text { NTA }\end{array}$ \\
\hline Tap water & $\begin{array}{c}\mathrm{Ag} \\
\mathrm{Ag} \\
\mathrm{ZnO} \\
\mathrm{Ag} \\
\end{array}$ & $\begin{array}{c}\text { SPE (magnetic matrix +acid etching) } \\
\text { Filtration }(0.45 \mu \mathrm{m}) \\
\mathrm{CPE}+\mathrm{MW} \\
\mathrm{CPE} \\
\end{array}$ & $\begin{array}{c}\text { ICP-MS } \\
\text { HDC-ICP-MS } \\
\text { TEM } \\
\text { ICP-MS } \\
\text { ET-AAS } \\
\end{array}$ \\
\hline Soil suspension & $\mathrm{ZnO}$ & Particles sedimentation & AF4-ICP-MS \\
\hline
\end{tabular}

* Abbreviations used in the table: AF4 - asymmetric flow field-flow fractation, CPE+MW - microwave assisted cloud point extraction, DLS - dynamic light scattering, EDS - energy dispersive X-ray spectroscopy, ESEM - environmental scanning electron microscopy, ET-AAS - electrothermal atomic absorption, EXAFS - extended X-ray absorption fine structure, FESEM - field-emission scanning electron microscopy, ICP-MS - inductively coupled plasma mass spectrometry, NTA - nanoparticle tracking analysis, PCC - particle collision coulometry, SPE - solid phase extraction, sp ICP-MS - single particle ICP-MS, TEM - transmission electron microscopy, VIP - voltammetry of immobilized particles, HDC-ICP-MS - hydrodynamic chromatography coupled to ICP-MS, UV-Vis - Ultraviolet-visible spectroscopy

In complex matrices, the separation of dissolved species from NPs before their determination might be required. For instance, dissolved $\operatorname{Ag}(\mathrm{I})$ can be physically separated by ultrafiltration, ultracentrifugation, and centrifugal ultrafiltration. Solidphase extraction (SPE) is currently one of the most widely practiced sample preparation procedures and has been shown to separate metal nanoparticles (MNPs) efficiently. Liquid phase extraction of hydrophilic NPs into water (also known as water-soluble NPs) and hydrophobic NPs into an organic solvent or a mixture of solvents has been reported for the purification and size separation of synthetic NPs. Cloud point extraction (CPE) was employed for the reversible extraction and separation of different NPs such as $\mathrm{Au}$, $\mathrm{TiO}_{2}$, multiwalled carbon nanotube (MWCNT), fullerene (C60) and $\mathrm{Fe}_{3} \mathrm{O}_{4}$ (Proulx et al., 2014; Mori, 2015; Mourdikoudis et al., 2018).

Several methods have been developed to analyse inorganic and organic nanoparticles (Table 1). The most common analytical methods for the determination of nanoparticles are field flow fractionation (FFF) with ICP-MS, HPLC or UHPLC coupled to high resolution mass spectrometry (HRMS), LC-UV and FFF coupled to HRMS, multi angle light scattering and dynamic light scattering. Recently, single particle inductively coupled plasma mass spectrometry (sp ICP-MS) was proposed for the simultaneous determination of NPs and dissolved ions of metals (Folens et al., 2018; Mozhayeva et al., 2019). sp ICP-MS is well suited to nanoparticle characterization as it provides determination of the particle number and size distribution, along with the concentration of both the particles and the dissolved element component. 
The objective of this study was to determine AgNPs size distribution and particles number concentration in environmental water samples. In this study AgNPs was chosen as the representative of metallic nanoparticles due to their broad applications and potential release into the environment.

\section{Materials and methods}

\section{Reference materials and sample preparation}

Alfa Aesar reference materials, such as AgNPs with a diameter of $20 \mathrm{~nm}$ and a concentration of $0.02 \mathrm{mg} / \mathrm{ml}$, AgNPs with a nominal diameter of $40 \mathrm{~nm} \pm 3 \mathrm{~nm}$ and a concentration of 0.02 $\mathrm{mg} / \mathrm{ml}$, AgNPs with a nominal diameter of $60 \mathrm{~nm} \pm 3 \mathrm{~nm}$ and a concentration of $0.02 \mathrm{mg} / \mathrm{ml}$ (used to determine nebulization efficiency, diluted in demineralized water to $200 \mathrm{ng} / \mathrm{l}$ ) and AgNPs with a nominal diameter of $100 \mathrm{~nm} \pm 3 \mathrm{~nm}$ and a concentration of $0.02 \mathrm{mg} / \mathrm{ml}$ were used for testing. Nanoparticles in reference solutions were stabilized by the manufacturer with $2 \mathrm{mM}$ sodium citrate. Reference materials and samples were diluted to $10-200 \mathrm{ng} / \mathrm{L}$ in deionized water and sonicated for 10 minutes before dilution and before analysis, with the addition of cooling cartridges to ensure sample homogeneity. Solutions were prepared on the day of analysis. To determine the response factor (cps/ppb), the Agma standard from Sigma Aldrich TraceCERT was used at a concentration of $0.994 \pm 0.003 \mathrm{mg} / \mathrm{l}$, which was diluted to $1 \mu \mathrm{g} / \mathrm{l}$ in $1 \%$ nitric acid solution $\left(\mathrm{HNO}_{3}\right)$.

Samples of surface water were taken with a hand scoop with a telescopic rod near Krakow (Poland). Samples of treated sewage were collected from a domestic sewage treatment plant located near a detached house in the vicinity of Krakow. Samples of the tap water were collected in polyethylene bottles directly from the tap after 3 minutes of draining the water from the tap. Water extract of waste from the oil and gas industry was prepared in accordance with PN-EN 12457-2:2006 and PN-EN 12457-4:2006 standards. More detailed information about samples collection object is in Table 2 .

Table 2. Description of the places of real samples collection

\begin{tabular}{|c|c|}
\hline Collected sample & $\begin{array}{l}\text { The description of the method and place of collection. } \\
\text { GPS coordinates }\end{array}$ \\
\hline $\begin{array}{l}\text { Water from supply system collected in } \\
\text { the area of Krakow }\end{array}$ & $\begin{array}{c}\text { Three samples of tap water were taken from three different taps in one } \\
\text { building in Krakow. } 50^{\circ} 02^{\prime} 15.9^{\prime \prime} \mathrm{N} 20^{\circ} 00^{\prime} 04.2^{\prime \prime} \mathrm{E}\end{array}$ \\
\hline $\begin{array}{l}\text { Water from supply system collected in } \\
\text { one of the villages near Krakow }\end{array}$ & $\begin{array}{c}\text { Two samples of water were collected from a tap located in a detached house } \\
\text { in one of the towns south of Krakow. } \\
49^{\circ} 58^{\prime} 41.3^{\prime \prime} \mathrm{N} 20^{\circ} 06^{\prime} 48.8^{\prime \prime} \mathrm{E}\end{array}$ \\
\hline Water from a drainage ditch & $\begin{array}{c}\text { Three water samples were collected from a ditch located in one of the towns } \\
\text { to the north of Krakow. } 50^{\circ} 08^{\prime} 51.7^{\prime \prime N} 20^{\circ} 05^{\prime} 25.6^{\prime \prime} \mathrm{E} \\
\end{array}$ \\
\hline $\begin{array}{l}\text { Water from the settling tank at a car } \\
\text { workshop }\end{array}$ & $\begin{array}{l}\text { Three water samples were taken from a settling tank at a car workshop in } \\
\text { one of the towns north of Krakow. } \\
50^{\circ} 08^{\prime} 44.3^{\prime \prime} \mathrm{N} 20^{\circ} 05^{\prime} 32.0^{\prime \prime} \mathrm{E}\end{array}$ \\
\hline $\begin{array}{l}\text { Treated sewage from domestic sewage } \\
\text { treatment system }\end{array}$ & $\begin{array}{l}\text { Treated sewage taken from a domestic sewage treatment system located } \\
\text { near a detached house in a village south of Krakow, } 3 \text { samples. } \\
49^{\circ} 58^{\prime} 41.5^{\prime \prime} \mathrm{N} 20^{\circ} 06^{\prime} 49.4^{\prime \prime} \mathrm{E}\end{array}$ \\
\hline Rainwater from storage tank & $\begin{array}{c}\text { Two samples taken from a rainwater storage tank situated near a house in a } \\
\text { locality north of Krakow. } \\
50^{\circ} 08^{\prime} 45.1^{\prime \prime} \mathrm{N} 20^{\circ} 05^{\prime} 32.0^{\prime \prime} \mathrm{E}\end{array}$ \\
\hline Surface water1 & $\begin{array}{l}\text { Water from a watercourse located in Krakow. } \\
50^{\circ} 02^{\prime} 00.8^{\prime \prime} \mathrm{N} 20^{\circ} 02^{\prime} 30.7^{\prime \prime} \mathrm{E}\end{array}$ \\
\hline Surface water2 & $\begin{array}{l}\text { Water from a watercourse located in a village south of Krakow. } \\
\qquad 50^{\circ} 02^{\prime} 04.6^{\prime \prime} \mathrm{N} 20^{\circ} 02^{\prime} 30.4^{\prime \prime} \mathrm{E}\end{array}$ \\
\hline Water extract from industrial waste & $\begin{array}{c}\text { Water extraction of waste from the oil and gas mining industry was } \\
\text { prepared (excavation after the application of polymer-potassium scrubber). }\end{array}$ \\
\hline
\end{tabular}


All studies were conducted in Krakow (Poland). All samples were stored without access to light at the temperature $2-5^{\circ} \mathrm{C}$. Before use, the bottles (and all flasks, pipettes and laboratory utensils used) were washed with $20 \%$ solution of $\mathrm{HNO}_{3}$. Samples were not stabilised and were analysed up to 24 hours after collection.

\section{Instrumentation}

The mass spectrometer ICP-MS 7900 from Agilent was used for measurements. Data acquisition was done using the Agilent Mass Hunter software in the time resolved analysis (TRA) mode with a $60 \mathrm{~s}$ acquisition time. ICP-MS was equipped with a standard MicroMist nebulizer, nickel cones, quartz burner $(1.0 \mathrm{~mm})$. The samples were introduced directly into the instrument using a peristaltic pump and $1.02 \mathrm{~mm}$ internal diameter tubing (sample flow velocity was $0.346 \mathrm{ml} / \mathrm{min}$ ). Prior to and between AgNPs analysis, the sample feed system was washed with $1 \% \mathrm{HNO}_{3}$.

The instrument was calibrated on the day of the analysis using Agilent solution $(1 \mu \mathrm{g} / \mathrm{l}$, $\mathrm{Li}, \mathrm{Co}, \mathrm{Y}, \mathrm{Tl}, \mathrm{Ce}, \mathrm{Baw} 2 \% \mathrm{HNO}_{3}$ ). The nebulization efficiency was in the range of 0.059-0.095. No internal standard was employed, because only ${ }^{107} \mathrm{Ag}$ was detected during the run. To ensure the absence of significant instrumental drift over time, a $200 \mathrm{ng} / \mathrm{l} \mathrm{Ag}$ dissolved standard was run in single particles mode for every 10 AgNPs samples analyzed.

The measurement parameters used in the NPs analysis are listed in Table 3.

Table 3. Parameters of analysis and mass spectrometer ( $s p$ ICP-MS) used for the determination of AgNPs

\begin{tabular}{c|c}
\hline Parameter $($ unit) & Value \\
\hline Power RF $(\mathrm{W})$ & 1550 \\
Carrier gas flow velocity $(\mathrm{l} / \mathrm{min})$ & 1.05 \\
Temperature of the mist chamber $\left({ }^{\circ} \mathrm{C}\right)$ & 2.0 \\
Nebulizer pump velocity (revolutions $/ \mathrm{min})$. & 0.1 \\
Sampling depth $(\mathrm{mm})$ & 8.0 \\
Integration time $(\mathrm{ms})$ & 0.5 \\
Data collection time $(\mathrm{s})$ & 60 \\
Data collection mode & $\mathrm{TRA}$ \\
Monitored weight & $107 \mathrm{Ag}$ \\
Density of particles $(\mathrm{g} / \mathrm{ml})$ & 10,5 \\
Mass fraction of Ag & 1 \\
\hline
\end{tabular}

The background equivalent diameter (BED) was calculated based on the results obtained. It allows to estimate the approximate smallest detectable NPs size. Mass equivalent to instrument noise ( $\mathrm{m}_{\mathrm{bkgnd}}$ - background equivalent mass) is expressed by the equation (Eq. 1) (Laborda et al., 2016):

$$
\begin{gathered}
m_{\text {bkgnd_rm }}=\frac{I_{\text {noise }}}{I_{r m}} \cdot m_{\text {std }} \\
m_{\text {bkgnd_unknown }}=I_{\text {noise }} \cdot \frac{1}{s} \cdot t_{d} \cdot V \cdot \eta_{\text {neb }} \cdot 10^{6} \cdot f_{d} \cdot \frac{1}{60}
\end{gathered}
$$


$\operatorname{BED}\left(\mathrm{d}_{\mathrm{bkgnd}}, \mathrm{nm}\right)$ can be calculated from dependency (Eq. 3):

$$
B E D=\sqrt[3]{\frac{6}{\pi} \cdot \frac{m_{\text {bkgnd }}}{10^{15} \cdot \rho_{p}}} \cdot 10^{7}
$$

where,

$I_{\text {noise }}$ - signal intensity for noise (cps)),

$I_{r m}$ - the arithmetic mean of the signal intensities for RM reference solutions (cps),

$m_{s t d}$ - particulate mass of the standard (fg),

$\mathrm{s}-$ response rate (cps/ppb),

$t_{d}$-integration time (s),

$\mathrm{V}$ - sample flow velocity ( $\mathrm{ml} / \mathrm{min})$,

$\eta_{n e b}$ - nebulisation efficiency,

$f_{d}$ - molar mass of the particle/analyte,

$\mathrm{T}$ - total time of data collection ( $\mathrm{min})$,

$\rho_{p}-$ density of particles $\left(\mathrm{g} / \mathrm{cm}^{3}\right)$.

\section{Results and discussion}

This paragraph presents the test results and determination of selected validation parameters for the developed method (such as background equivalent diameter, correctness, recovery, NPs stability over time and reproducibility).

\section{Background equivalent diameter (BED)}

Equation 3 shows that BED depends on the effectiveness of nanoparticle detection. Therefore, the improvement of ionization conditions for elements with a low ionization potential, as well as the increase of ion transmission through the use of more efficient instrumental systems, may reduce the limit of particle size detection. sp ICP-MS allows to detect nanoparticles of metal above $\sim 20 \mathrm{~nm}$, while the size of oxides increases depending on their stoichiometry. In terms of mass, the detection limits are about tens of attograms per NP (Laborda et al., 2016).

The value of the smallest detectable size (BED) of silver nanoparticles obtained for the implemented method is $9-15 \mathrm{~nm}$. The values obtained are similar to those provided in literature (Laborda et al., 2016). No partial results were reported due to their large number. BED was determined by the instrument for each sample.

\section{Correctness of the method}

Correctness of measurement means the conformity of a test value with a true value or an accepted reference value. Most often, correctness is expressed in terms of load, i.e. total systematic error. In order to determine the load (and verify the correctness), a standard is added, and a recovery calculation is used.

Tables 4-6 summarise the test results obtained for reference materials. Table 4 shows the results obtained for a series of reference solutions with a nominal diameter of $20 \mathrm{~nm}$; Table 5 shows the results obtained for a series of reference solutions with a nominal diameter of $40 \mathrm{~nm}$; and Table 6 shows the results obtained for a material with a diameter of $60 \mathrm{~nm}$. The correctness of the method is expressed as a percentage of recovery. 
Table 4. Results obtained for a series of reference solutions with a nominal diameter of $20 \mathrm{~nm}$

\begin{tabular}{c|c|c|c}
\hline Parameter & $\begin{array}{c}\text { Nominal diameter - } \\
\text { mean * [nm] }\end{array}$ & $\begin{array}{c}\text { Number of particles } \\
\text { [particles/l] }\end{array}$ & $\begin{array}{c}\text { Concentration of } \\
\mathbf{A g}[\boldsymbol{\mu g} / \mathbf{l}]\end{array}$ \\
\hline Value provided by manufacturer & 20.0 & Not provided & 0.050 \\
Measured value (n=6)* & 25.58 & $8.04 \cdot 10^{7}$ & 0.045 \\
Recovery [\%] & 128 & - & 90 \\
Value provided by manufacturer & 20 & Not provided & 0.100 \\
Measured value $(\mathrm{n}=4)^{* *}$ & 20.91 & $6.25 \cdot 10^{7}$ & 0.114 \\
Recovery [\%] & 104.6 & - & 114 \\
\hline
\end{tabular}

Table 5. Results obtained for a series of reference solutions with a nominal diameter of $40 \mathrm{~nm}$

\begin{tabular}{c|c|c|c}
\hline Parameter & $\begin{array}{c}\text { Nominal diameter- } \\
\text { mean }[\mathbf{n m}]\end{array}$ & $\begin{array}{c}\text { Number of particles } \\
{[\text { particles/l] }}\end{array}$ & $\begin{array}{c}\text { Concentration of } \\
\mathbf{A g}[\boldsymbol{\mu g} / \mathbf{l}]\end{array}$ \\
\hline Value provided by manufacturer & $40 \pm 3 \mathrm{~nm}$ & $4.25 \cdot 10^{7}$ & 0.050 \\
Measured value (n=6) & 40.1 & $3.99 \cdot 10^{7}$ & 0.051 \\
Recovery [\%] & 100 & 93.8 & 102 \\
\hline
\end{tabular}

Table 6. Results obtained for a series of reference solutions with a nominal diameter of $60 \mathrm{~nm}$

\begin{tabular}{c|c|c|c}
\hline Parameter & Nominal diameter-mean [nm] & Number of particles/L & $\begin{array}{c}\text { Concentration of } \\
\mathbf{A g}[\boldsymbol{\mu g} / \mathbf{l}]\end{array}$ \\
\hline Value provided by manufacturer & $60 \pm 3 \mathrm{~nm}$ & $1.7 \cdot 10^{8}$ & 0.200 \\
Measured value & 54.4 & $1.72 \cdot 10^{8}$ & 0.219 \\
(n=4) & 90.7 & 101 & 110 \\
Recovery [\%] & $60 \pm 3 \mathrm{~nm}$ & $8.50 \cdot 10^{7}$ & 0.200 \\
Value provided by manufacturer & 62.5 & $7.15 \cdot 10^{7}$ & 0.218 \\
Measured value (n=4) & 104 & 84,1 & 109 \\
Recovery [\%] & $60 \pm 3 \mathrm{~nm}$ & $1.7 \cdot 10^{8}$ & 0.200 \\
Value provided by manufacturer & 54.4 & $1.72 \cdot 10^{8}$ & 0.219 \\
Measured value & 90.7 & 101 & 110 \\
(n=4) & $60 \pm 3 \mathrm{~nm}$ & $1.7 \cdot 10^{8}$ & 0.200 \\
Recovery [\%] & 63.6 & $1.51 \cdot 10^{8}$ & 0.218 \\
Value provided by manufacturer & 106 & 89 & 109 \\
Measured value (n=6) & & & \\
Recovery [\%] & &
\end{tabular}

The recovery obtained for the number of particles/L was within the range of $84.1-101 \%$, while the recovery determined for the nominal diameter was within the range of $90.7-128 \%$. The recovery value for the nominal diameter of $128 \%$ was obtained for particles of $20 \mathrm{~nm}$ size, which are close to LOD $_{\text {size. }}$.

On the basis of the conducted research and calculations it can be stated that the validated method of determination of AgNPs by sp ICP-MS is correct.

Figure 1 shows the particle size distribution for reference solutions of $20 \mathrm{~nm}$ (a), $40 \mathrm{~nm}$ (b), $60 \mathrm{~nm}$ (c) Ag NPs.

The resulting particle size distributions are wide. Reference materials are crucial for checking the quality and metrological traceability of analytical results. They are also essential for the validation of particle size analysis methods and instrument calibration. The number of reference materials for nanoparticle analysis is currently limited. In addition, matrix reference materials for nanoparticles are not commercially available. 
Therefore, NP calibrators that are used to calibrate methods and for initial experiments should be characterized by size and size distribution (homogeneity) using scanning electron microscopy (SEM) and transmission electron microscopy (TEM).
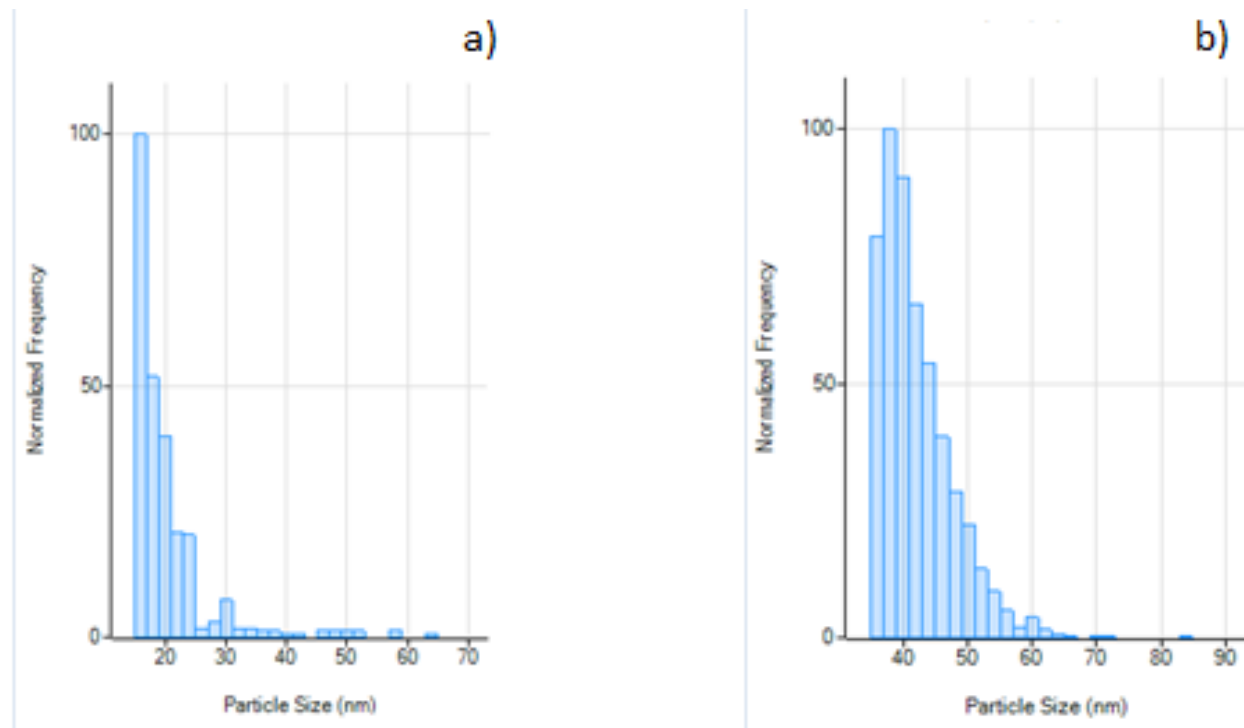

c)

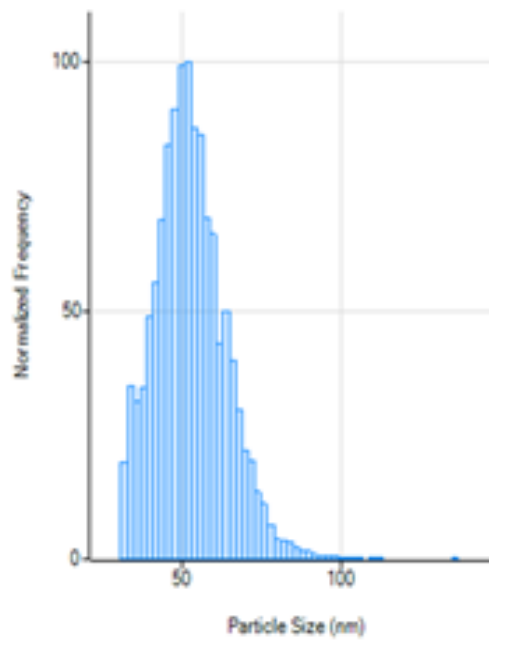

Figure 1. Particle size distribution for 20, 40 and $60 \mathrm{~nm} \mathrm{AgNPs}$

\section{Reproducibility}

Reproducibility is the degree of agreement between independent test results obtained under steady state conditions. Reproducibility does not refer to an actual value or other specified value. It depends only on the distribution of random errors and is a concept that describes the variability of repeated results. The reproducibility measure is usually taken as the standard deviation of the test results (the standard deviation of the sample). The higher the standard deviation, the lower the precision. RSD, i.e. relative standard deviation, is most commonly used to assess reproducibility. 
Table 7 shows the measurement results used to determine the reproducibility of the method. The reproducibility of the method has been determined in $\%$ as the RSD (Relative Standard Deviation).

Table 7. Measurement results used to determine the reproducibility of a method

\begin{tabular}{c|c|c}
\hline Value provided by manufacturer & Measured diameter [nm] & RSD [\%] \\
\hline \multirow{2}{*}{$60 \pm 3 \mathrm{~nm}$} & 62.0 & 0.366 \\
& 62.8 & \\
\hline $20 \mathrm{~nm}$ & 62.0 & 4.3 \\
\hline
\end{tabular}

Calculated RSD values do not exceed 5\%. The method is reproducible for the tested range

\section{Recovery}

Example results of analyses of mixtures prepared from real samples (surface waters) with the addition of a reference material with a particle size of $60 \mathrm{~nm}$ are presented in Table 8. Recovery was calculated for the mass concentration of Ag.

Table 8. Results of analyses of mixtures prepared from real samples

\begin{tabular}{c|c|c|c|c|c}
\hline Matrix & $\begin{array}{c}\text { Mean diameter } \\
\text { of particles } \\
{[\mathbf{n m}]}\end{array}$ & $\begin{array}{c}\text { Most common } \\
\text { particle size } \\
{[\mathbf{n m}]}\end{array}$ & $\begin{array}{c}\text { Number of } \\
\text { particles per L }\end{array}$ & $\begin{array}{c}\text { Recovery } \\
\text { Mass } \\
\text { concentration } \\
\text { [ng NPs/L] }\end{array}$ & $\begin{array}{c}\text { determined for } \\
\text { mass } \\
\text { concentration } \\
{[\%]}\end{array}$ \\
\hline $\begin{array}{c}\text { Surface water 1 } \\
\text { Surface water 1+60 nm } \\
\text { NPs }(100 \mu \mathrm{g} / \mathrm{l})\end{array}$ & 51.4 & 50.7 & $1.71 \cdot 10^{8}$ & 150.3 & 106 \\
$\quad \begin{array}{c}\text { Surface water 2 } \\
\text { Surface water 2 }+60 \mathrm{~nm} \\
\text { NPs }(100 \mu \mathrm{g} / \mathrm{l})\end{array}$ & 23.2 & 20.4 & $1.83 \cdot 10^{8}$ & 14.3 & 86 \\
\hline
\end{tabular}

The recovery values are $86 \%$ and $106 \%$. After adding the $60 \mathrm{~nm}$ standard to the analyzed samples, the number of particles/L decreased. More tests would be needed to determine the cause of this dependency (e.g. checking particle size distribution, agglomeration, optimising sonication parameters and sonication efficiency after adding the standard to the sample, tests for more diluted samples).

\section{Stability of nanoparticles over time}

Measurements were taken for the reference material $60 \mathrm{~nm}$ on the day of solution preparation and for the same solution 10 days after preparation. The reference solution was stored in the dark and cooled to $2-5^{\circ} \mathrm{C}$. The results of the particle size distribution are shown in Figures $2 a$ ) and $2 b$ ) and Table 9.

On the basis of the conducted research it can be stated that Ag nanoparticles are not stable in aqueous solution. It is necessary to keep the samples in the dark, to cool them and possibly to add a stabilising agent to the sample, e.g. sodium citrate or 3-aminopropyltrimethoxysilane. 

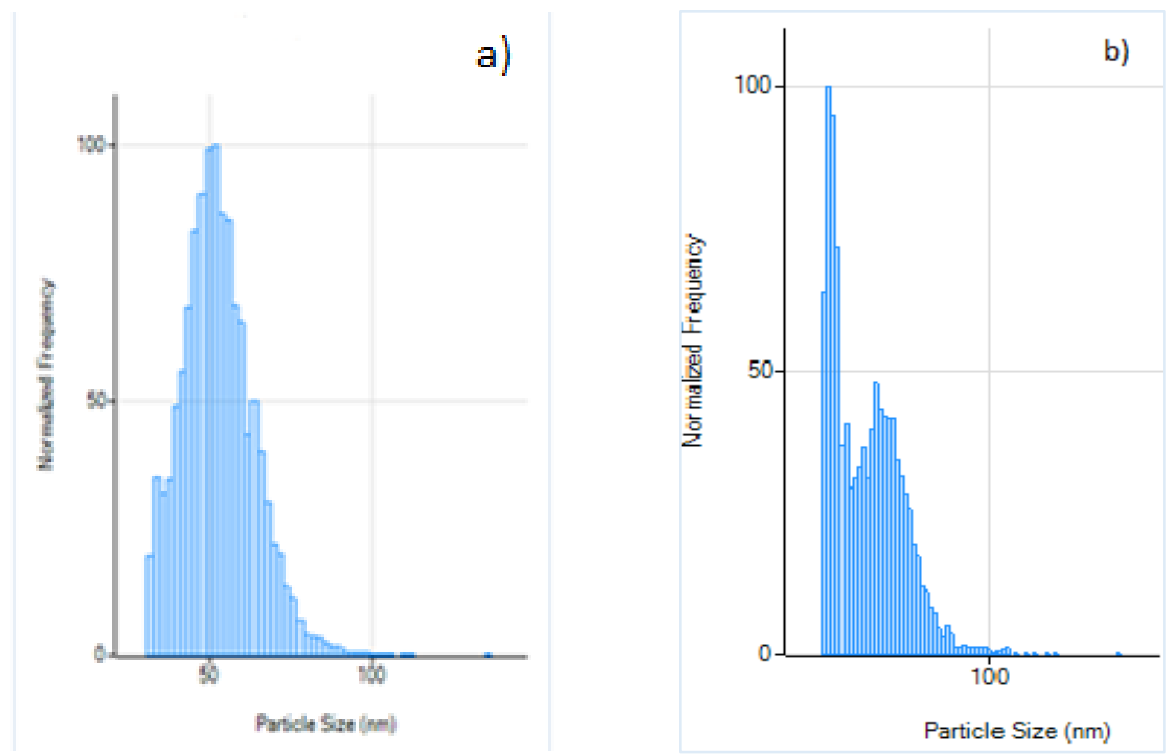

Figure 2. Particle size distribution for a) $60 \mathrm{~nm}$ reference material prepared on the day of determination b) results 10 days after preparation of the solution

Table 9. Testing for stability of nanoparticles

\begin{tabular}{c|c|c}
\hline Reference solution & Most common size [nm] & Mean size of particles [nm] \\
\hline $60 \mathrm{~nm}$ & 48 & 56.6 \\
$60 \mathrm{~nm}$ after 10 days & 24 & 41.2 \\
\hline
\end{tabular}

Nanoparticles can undergo many transformations under biological or environmental conditions. Primary nanoparticles may form larger agglomerates or aggregates, being reversible only in the first case. On the other hand, some metal-containing NPs (e.g. silver, zinc oxide) may dissolve, releasing soluble compounds.

Analysis of the data in Table 10 shows that silver nanoparticles have been found in all environmental samples analysed. The most common nanoparticles were those of the sizes $16-28 \mathrm{~nm}$.

The highest content of AgNPs was determined for one of the samples of water taken from a drainage ditch $(76 \mathrm{ng} / \mathrm{l})$. However, the total concentration obtained for this sample is not the highest. The highest concentration of silver was determined in the sample of tap water taken in Krakow. The total Ag content obtained for tap water samples does not exceed the limit given in the Minister of Health's Ordinance of 7 December 2017 on the quality of water intended for human consumption $(0.010 \mathrm{mg} / \mathrm{l})$. However, if the obtained silver concentration values were close to the limit value given in the regulation, it would be advisable to make a particle size distribution and check if the smallest size particles that may have toxic properties do not constitute a large proportion in this distribution.

The analysis of environmental samples shows that there is no direct correlation between the amount of silver nanoparticles and the concentration of silver in the sample, and therefore the interpretation of environmental data is difficult and requires the analysis of many factors. 
Table 10. Results obtained for real samples

\begin{tabular}{|c|c|c|c|c|c|}
\hline Matrix & $\begin{array}{c}\text { Mean } \\
\text { particle } \\
\text { diameter } \\
{[\mathrm{nm}]} \\
\end{array}$ & $\begin{array}{l}\text { Most common } \\
\text { particle size in a } \\
\text { sample }[\mathrm{nm}]\end{array}$ & $\begin{array}{l}\text { Number of } \\
\text { particles/L }\end{array}$ & $\begin{array}{c}\text { Mass } \\
\text { concentration of } \\
\text { AgNPs [ng/l] }\end{array}$ & $\begin{array}{c}\text { Concentration of } \\
\operatorname{Ag}[\mu \mathrm{g} / \mathrm{I}]\end{array}$ \\
\hline \multirow{3}{*}{$\begin{array}{c}\text { Water from supply } \\
\text { system collected in the } \\
\text { area of Krakow }\end{array}$} & 20.1 & 18 & $1.56 \cdot 10^{7}$ & $<0.10$ & 0.9761 \\
\hline & 29.6 & 18 & $1.94 \cdot 10^{7}$ & $<0.10$ & 5.112 \\
\hline & 16.2 & 16 & $9.35 \cdot 10^{6}$ & 0.341 & 0.0076 \\
\hline \multirow{2}{*}{$\begin{array}{c}\text { Water from supply } \\
\text { system collected in one } \\
\text { of the villages near } \\
\text { Krakow }\end{array}$} & 19.01 & 16 & $3.57 \cdot 10^{7}$ & 2.18 & 0.0095 \\
\hline & 19.18 & 16 & $2.07 \cdot 10^{7}$ & 1.23 & 0.0065 \\
\hline \multirow{3}{*}{$\begin{array}{l}\text { Water from a drainage } \\
\text { ditch }\end{array}$} & 33.3 & 24 & $2.68 \cdot 10^{8}$ & 76.00 & 0.1059 \\
\hline & 21.7 & 20 & $2.33 \cdot 10^{8}$ & 14.35 & 0.0430 \\
\hline & 21.5 & 22 & $1.99 \cdot 10^{8}$ & 11.90 & 0.0402 \\
\hline \multirow{3}{*}{$\begin{array}{l}\text { Water from the settling } \\
\text { tank at the car workshop }\end{array}$} & 21.5 & 22 & $2.06 \cdot 10^{8}$ & 12.43 & 0.041 \\
\hline & 20.0 & 18 & $2.00 \cdot 10^{8}$ & 11.84 & 0.036 \\
\hline & 19.9 & 18 & $1.53 \cdot 10^{8}$ & 7.42 & 0.030 \\
\hline \multirow{2}{*}{$\begin{array}{c}\text { Rainwater from storage } \\
\text { tank }\end{array}$} & 31.51 & 26 & $2.95 \cdot 10^{7}$ & 8.075 & 0.085 \\
\hline & 21.81 & 20 & $9.87 \cdot 10^{6}$ & 0.648 & 0.021 \\
\hline \multirow{3}{*}{$\begin{array}{l}\text { Treated sewage from } \\
\text { domestic sewage } \\
\text { treatment system }\end{array}$} & 18.6 & 18 & $8.24 \cdot 10^{7}$ & 4.11 & 0.0183 \\
\hline & 17.9 & 16 & $1.28 \cdot 10^{8}$ & 4.54 & 0.0215 \\
\hline & 18.0 & 18 & $9.10 \cdot 10^{7}$ & 3.29 & 0.0184 \\
\hline Surface water1 & 18.1 & 17 & $1.42 \cdot 10^{7}$ & 0.860 & 0.008 \\
\hline Surface water2 & 23.2 & 20 & $1.53 \cdot 10^{8}$ & 14.25 & 0.029 \\
\hline Water extract of waste & 30.00 & 28 & $1.00 \cdot 10^{7}$ & 4.00 & 0.142 \\
\hline
\end{tabular}

The graph showing the number of counts as a function of CPS time (counts per second) and the particle size distribution for a sample of tap water taken in Krakow is presented in Figure 3. The analyzed sample contained nanoparticles of different sizes. The mean diameter of particles was $16.2 \mathrm{~nm}$, but there were also nanoparticles with a diameter above $50 \mathrm{~nm}$. The particle size distribution was wide.

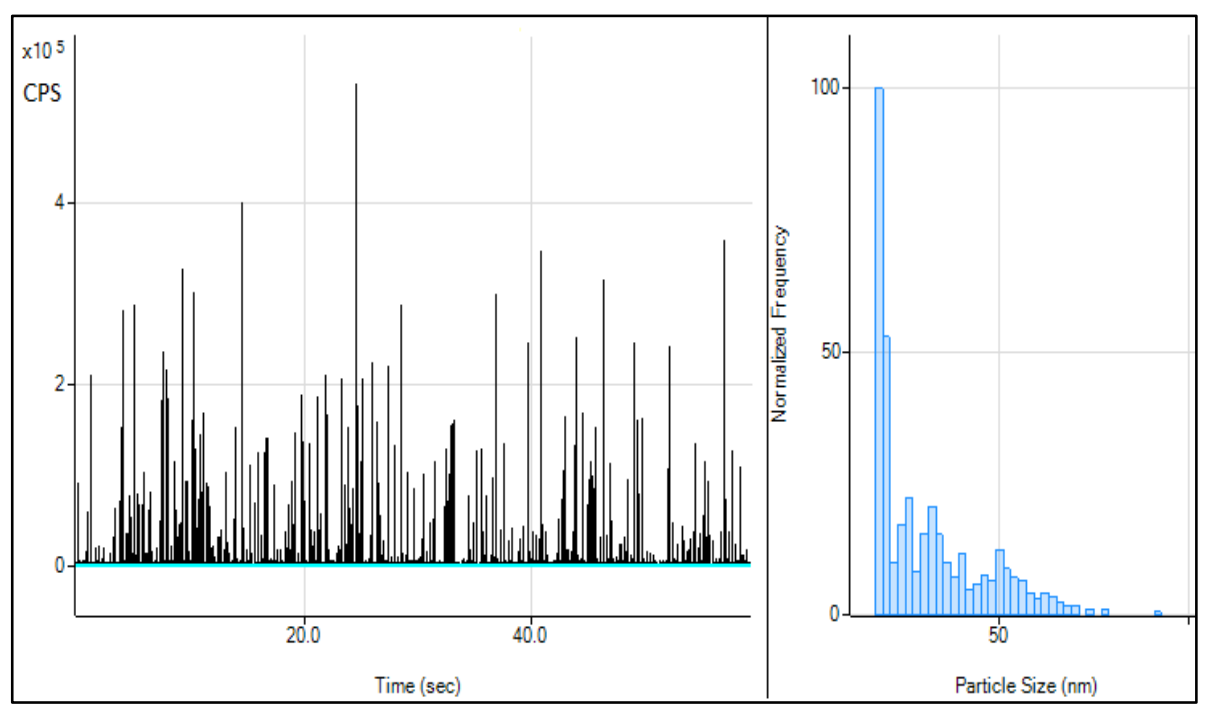

Figure 3. CPS (counts per second) as a function of time and the particle size distribution for the sample of tap water collected in Krakow 


\section{Conclusions}

At present, the scale of nanoparticles' applications is enormous, which means that their presence in the environment is becoming more and more common. Nanoparticles are separated by centrifugation, ultrafiltration, cloud point extraction (CPE) and flow fractionation in an asymmetric flow force field (AF4). The most popular methods of nanoparticles determination in environmental samples are: Nanoparticle Tracking Analysis (NTA), Dynamic Light Scattering (DLS), Scanning Electron Microscopy (SEM) and Inductively Coupled Plasma Mass Spectrometry (ICP-MS, sp ICP-MS). The literature review confirmed that sp ICP-MS technique is a sensitive, effective, fast and modern technique used for the determination of metal nanoparticles in environmental samples.

The method of determination of Ag nanoparticles in liquid environmental samples using sp ICP-MS has been validated. Reproducibility, correctness, recovery, BED and stability of nanoparticles were determined. Validation of the analytical method showed its ability to determine silver nanoparticles in the matrices tested.

The results of tests of liquid real samples confirm the presence of Ag nanoparticles in the analyzed samples (e.g. environmental samples and aqueous extracts of mining waste). Nanosilver was present in most of the analysed samples at concentrations of $0.291-76 \mathrm{ng} / \mathrm{l}$. The mean diameter of AgNPs in the examined samples was in the range of 16.2-33.3 nm. Silver nanoparticles were also found in tap water and their sizes were widely distributed over the whole range of nanometre size. The mean diameter of nanoparticles in tap water was 16.2-29.6 $\mathrm{nm}$, which is quite disturbing as nanoparticles smaller than $100 \mathrm{~nm}$ can easily penetrate cell membranes and cause damage to all cells, including organs and brain (Zhang et al., 2019). Particle size is the main factor affecting the toxicity of AgNPs (Cho et al., 2018). The determined particle sizes are comparable to those used in nanomaterials and consumer products (Kessler, 2011).

The total Ag content obtained for tap water samples does not exceed the limit given in the Minister of Health's Ordinance of 7 December 2017 on the quality of water intended for human consumption but it would be advisable to perform a particle size distribution for samples with a concentration near the limit value given in the regulation.

Determination of NPs in environmental matrices has not been carried out in Poland so far. This study improves the knowledge on the quality of drinking and surface waters, indicates the presence of nanoparticles in environmental samples and aqueous extracts of mining waste. However, it is necessary to conduct more tests on NPs content and to extend the validation to other parameters and matrices, given the potential impact of NPs on human health. In addition, other methods of nanoparticle separation found in literature should be examined and the parameters for separating NPs from the matrix should be optimized.

\section{REFERENCES}

[1] Aznar, R., Barahona, F., Geiss, O., Ponti, J., José Luis, T., Barrero-Moreno, J. (2017): Quantification and size characterisation of silver nanoparticles in environmental aqueous samples and consumer products by single particle-ICPMS. - Talanta 175: 200-208.

[2] Bundschuh, M., Filser, J., Lüderwald, S., Mckee, M. S., Metreveli, G., Schaumann, G. E., Schulz, R., Wagner, S. (2018): Nanoparticles in the environment: where do we come from, where do we go to? - Environ. Sci. Eur. 30(1): 6. 
[3] Cho, Y. M., Mizuta, Y., Akagi, J. I., Toyoda, T., Sone, M., Ogawa, K. (2018): Sizedependent acute toxicity of silver nanoparticles in mice. - J Toxicol Pathol. 31(1): 73-80.

[4] Folens, K., Van Acker, T., Bolea-Fernandez, E., Cornelis, G., Vanhaecke, F., Du Laing, G., Rauch, S. (2018): Identification of platinum nanoparticles in road dust leachate by single particle inductively coupled plasma-mass spectrometry. - Science of The Total Environment 615: 849-856.

[5] Kessler, R. (2011): Engineered Nanoparticles in Consumer Products: Understanding a New Ingredient. - Environ Health Perspect. 119(3): A120-A125.

[6] Kim, B., Park, C. S., Murayama, M., Hochella, M. F. Jr. (2010): Discovery and characterization of silver sulfide nanoparticles in final sewage sludge products. - Environ. Sci. Technol. 44(19): 7509-7514.

[7] Krasodomski, M., Krasodomski, W., Ziemiański, L. (2009): Nanotechnologia a przemysł naftowy. - Nafta-Gaz 65(1): 83-92.

[8] Krasodomski, W., Rembiesa-Śmiszek, A., Skibińska, A. (2013): Nanocząstki w środkach smarowych. - Nafta-Gaz 69(3): 220-225.

[9] Laborda, F., Bolea, E., Cepriá, G., Gómez, M. T., Jiménez, M. S., Pérez-Arantegui, J., Castillo, J. R. (2016): Detection, characterization and quantification of inorganic engineered nanomaterials: A review of techniques and methodological approaches for the analysis of complex samples. - Anal Chim Acta 904: 10-32.

[10] Majedi, S. M., Lee, H. K. (2016): Recent advances in the separation and quantification of metallic nanoparticles and ions in the environment. - TrAC Trends in Analytical Chemistry 75: 183-196.

[11] Mori, Y. (2015): Size-Selective Separation Techniques for Nanoparticles in Liquid. KONA Powder and Particle Journal 32: 102-114.

[12] Mourdikoudis, S., Pallares, R. M., Thanh, N. T. K. (2018): Characterization techniques for nanoparticles: comparison and complementarity upon studying nanoparticle properties. Nanoscale 10: 12871-12934.

[13] Mozhayeva, D., Engelhard, C. (2019): A critical review of sp ICP MS - A step towards an ideal method for nanomaterial characterization. - J. Anal. At. Spectrom., published online, DOI: $10.1039 / \mathrm{c} 9 \mathrm{ja00206e.}$

[14] Prasad, R., Kumar, M., Kumar, V. (2017): Nanotechnology. - Springer Nature Singapore Pte Ltd., ISBN 978-981-10-4572-1.

[15] Proulx, K., Wilkinson, K. J. (2014): Separation, detection and characterisation of engineered nanoparticles in natural waters using hydrodynamic chromatography and multimethod detection (light scattering, analytical ultracentrifugation and single particle ICPMS). - Environ. Chem. 11: 392-401.

[16] Wagner, S., Gondikas, A., Neubauer, E., Hofmann, T., Von Der Kammer, F. (2014): Spot the difference: engineered and natural nanoparticles in the environment - release, behaviour, and fate. - Angewandte Chemie International 53: 12398-12419.

[17] Weinberg, H., Galyean, A., Leopold, M. (2011): Evaluating engineered nanoparticles in natural waters. - TrAC Trends Anal Chem. 30(1): 72-83.

[18] Zhang, M., Yang, J., Cai, Z., Feng, Y., Wang, Y., Zhang, D., Pan, X. (2019): Detection of engineered nanoparticles in aquatic environments: current status and challenges in enrichment, separation, and analysis. - Environmental Science: Nano 6: 709-735.

[19] Zima, G. (2017): Analiza wpływu nanomateriałów na właściwości osadu filtracyjnego. Nafta-Gaz 73(5): 312-320. 